OPEN ACCESS

Edited by:

Phil Renforth,

Heriot-Watt University,

United Kingdom

Reviewed by:

Elisabeth A. Graffy,

Arizona State University, United States

Rafael Mattos Dos Santos,

University of Guelph, Canada

*Correspondence:

Eric Dunford

edunford@carboncure.com

Specialty section

This article was submitted to Negative Emission Technologies,

a section of the journal

Frontiers in Climate

Received: 27 March 2021 Accepted: 01 September 2021 Published: 27 September 2021

Citation:

Dunford E, Niven R and Neidl C (2021) Deploying Low Carbon Public Procurement to Accelerate Carbon Removal. Front. Clim. 3:686787. doi: 10.3389/fclim.2021.686787

\section{Deploying Low Carbon Public Procurement to Accelerate Carbon Removal}

\author{
Eric Dunford ${ }^{1 *}$, Robert Niven ${ }^{1}$ and Christopher Neidl ${ }^{2}$ \\ ${ }^{1}$ CarbonCure Technologies, Dartmouth, NS, Canada, ${ }^{2}$ OpenAir Collective, New York City, NY, United States
}

Carbon dioxide removal (CDR) will be required to keep global temperature rise below $2^{\circ} \mathrm{C}$ based on IPCC models. Greater adoption of carbon capture utilization and storage (CCUS) technologies will drive demand for CDR. Public procurement of low carbon materials is a powerful and under-utilized tool for accelerating the development and of CCUS through a targeted and well-regulated approach. The policy environment is nascent and presents significant barriers for scaling and guiding emerging technology solutions. The concrete sector has unique attributes that make it ideally suited for large-scale low-carbon public procurement strategies. This sector offers immediate opportunities to study the efficacy of a supportive policy and regulatory environment in driving the growth of CCUS solutions.

Keywords: carbon utilization, carbon removal, CCUS, low carbon public procurement, climate policy

\section{INTRODUCTION}

The Intergovernmental Panel on Climate Change (IPCC) has identified that all pathways limiting global warming to $1.5^{\circ} \mathrm{C}$ include removal of carbon dioxide from the atmosphere in addition to aggressive mitigation of greenhouse gas emissions (Rogelj et al., 2018). Ten gigatonnes of $\mathrm{CO}_{2}$ must be removed from the atmosphere each year by 2050 to keep temperature rise below $2^{\circ} \mathrm{C}$ (Mulligan et al., 2020). Carbon dioxide removal from the atmosphere, or CDR, is defined as:

"Anthropogenic activities removing $\mathrm{CO}_{2}$ from the atmosphere and durably storing it in geological, terrestrial, or ocean reservoirs, or in products. It includes existing and potential anthropogenic enhancement of biological or geochemical sinks and direct air capture and storage but excludes natural $\mathrm{CO}_{2}$ uptake not directly caused by human activities" (Masson-Delmotte et al., 2018).

Complete $\mathrm{CDR}$ solutions therefore must consist of two components: $\mathrm{CO}_{2}$ capture from the atmosphere, and an endpoint where $\mathrm{CO}_{2}$ is stored in geological or biological sinks or utilized within the production of economically valuable products. Multiple pathways have been identified for carbon removal, including the enhancement of natural systems (e.g., reforestation and agricultural soil management), and engineered approaches (e.g., direct air capture and enhanced mineralization).

Private sector entities have long utilized their purchasing power to influence their respective supply chains, a strategy increasingly deployed to achieve sustainability goals. This has been a consequential development as indirect emissions arising from the supply chain (referred to as Scope 3 emissions) account for as much as $75 \%$ of an organization's carbon footprint (Huang et al., 2009). Meta-analyses of sustainable supply chain studies indicate that deployment of capital to promote 
sustainable practices has a positive impact on operational and financial performance, especially for manufacturing industries (Govindan et al., 2020).

Private firms are now turning their attention toward the CDR challenge. This effort has been led by the information technology sector, with multiple firms (including Microsoft, Shopify, and Stripe) investing in research and development and the direct purchasing of carbon credits from CDR technology providers. Early private subsidization of innovation is enabling the continued development of nascent technologies and fueling investment interest. Private investment alone however will be insufficient to drive the advancement of CDR at the scale and rate necessary to avoid overshooting the $2^{\circ} \mathrm{C}$ target.

Federal, state, and local public agencies are the largest overall spenders in the market and have unmatched capacity to use their procurement to advance key policy objectives. Public procurement accounts for $\sim 13 \%$ of the gross domestic product of OECD countries (Baron, 2016). The scope and scale of public procurement makes it one of the most effective policy mechanisms available to governments to drive emissions reductions (Correia et al., 2013; Grandia and Meehan, 2017). Government agencies are expected to deliver the best value to civil society as stewards of public funds. Increasingly, this has come to mean the delivery of outcomes that offer a broader public benefit than purchasing the right material at the right quantity and best price. Recent studies have shown that citizens support the concept of public agencies using their buying power to deliver environmental benefits (Keulemans and Van de Walle, 2017).

Data on public views of CDR is more limited. A recent survey indicates that despite low awareness of CDR and skepticism that it will address root causes of climate change, there is public support for CDR provided it is pursued as part of a larger decarbonization agenda and not as a substitute for mitigation (Cox et al., 2020).

\section{Low Carbon Procurement Policy Overview}

Despite its potential impact and signs of support, there are few examples of public policy that target carbon reduction through procurement. As CDR is an emerging policy interest, governments have preferred to fund grants that support technology research and development and to provide tax subsidies for private entities investing in innovation. Low carbon procurement policies directly promote deployment by linking policy goals for decarbonization to the purchasing of materials. This requires government agencies to choose a tender design that awards a contract based on criteria other than price (Grandia and Meehan, 2017).

Government procurement focusing on lower carbon products would stimulate demand for carbon capture and utilization (CCUS) technologies that reduce the carbon content of materials vs. conventionally manufactured products. This would not necessarily lead to increased demand for CDR as the utilized $\mathrm{CO}_{2}$ could come from industrial point sources. Growth of market segments that utilize carbon dioxide however would increase demand for $\mathrm{CO}_{2}$ overall, potentially spurring greater investment in CDR.

The most prominent low carbon procurement policy model in North America is the Buy Clean California Act. Buy Clean directs state agencies to consider the carbon impact of materials purchased for infrastructure projects (Buy Clean California Act, 2017). Notably, Buy Clean does not yet cover all classes of materials, including emissions-intensive materials such as aluminum, wood, concrete, and cement. Similar legislation was recently adopted in Colorado, suggesting that it will be broadly applicable in the United States.

\section{Cement and Concrete}

Consumption of concrete materials is deeply interconnected with public spending, with public sector infrastructure one of the two largest drivers of concrete production. As much as $39 \%$ of all concrete in North America is purchased by public agencies (Hasanbeigi and Khutal, 2021). Research by the City of Portland, Oregon suggests that concrete is the single largest source of carbon in the supply chain for local governments (Trucost, 2016). This is largely due to the impact of Ordinary Portland Cement, the key binding ingredient in conventional concrete products. Cement is an inherently emissions-intensive industrial material that is difficult to decarbonize. Cement production generates $\sim 7 \%$ of annual global emissions (Figure 1) (Czigler et al., 2020).

The absence of cement and concrete from Buy Clean is notable and to date, there is no low carbon procurement policy enacted at a state or federal level that connects decarbonization policy objectives with the carbon impact of these materials. Beyond its importance as a significant source of Scope 3 emissions, concrete has the ability to mineralize $\mathrm{CO}_{2} \cdot \mathrm{CO}_{2}$ can be utilized as a substitute, input, or enhancement for the various constituent materials of conventional concrete, including water, cement, aggregates, and supplementary cementitious materials (Cao et al., 2021).

Multiple early-stage companies are already active in this space that is expected to achieve 1-5Gt of carbon removal per year (refer to Figure 2). The market for $\mathrm{CO}_{2}$ utilization in concrete products is expected to grow to $\$ 150-\$ 400 \mathrm{~B}$ by 2030 with $50 \%$ of all $\mathrm{CO}_{2}$ reductions in the sector expected to come from carbon capture and utilization $\left(\mathrm{CO}_{2}\right.$ Sciences The Global $\mathrm{CO}_{2}$ Initiative, 2016). This early innovation, combined with the fact that concrete is the most widely used human-made material in the world,

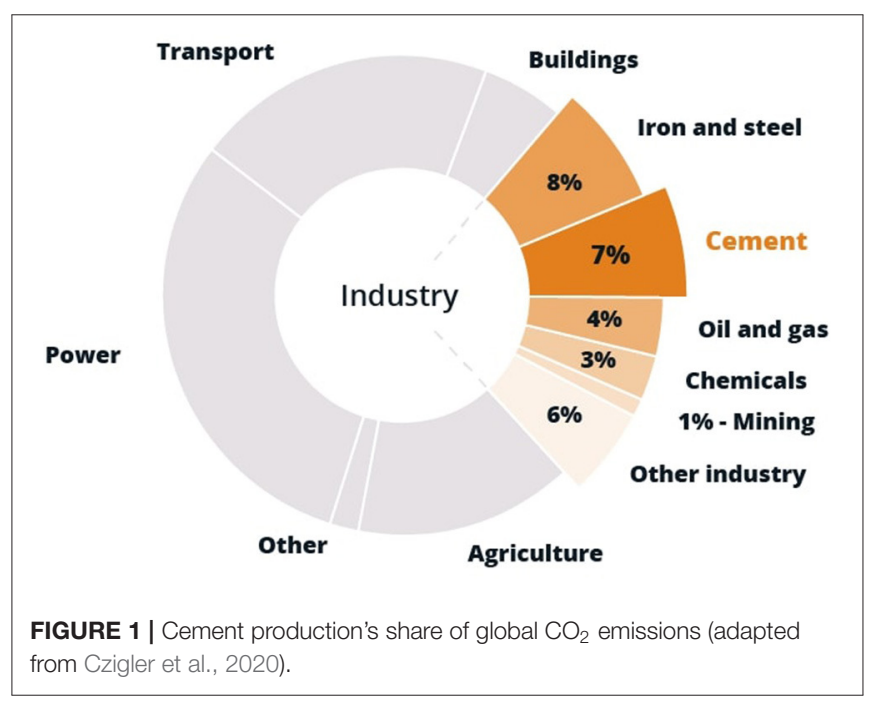




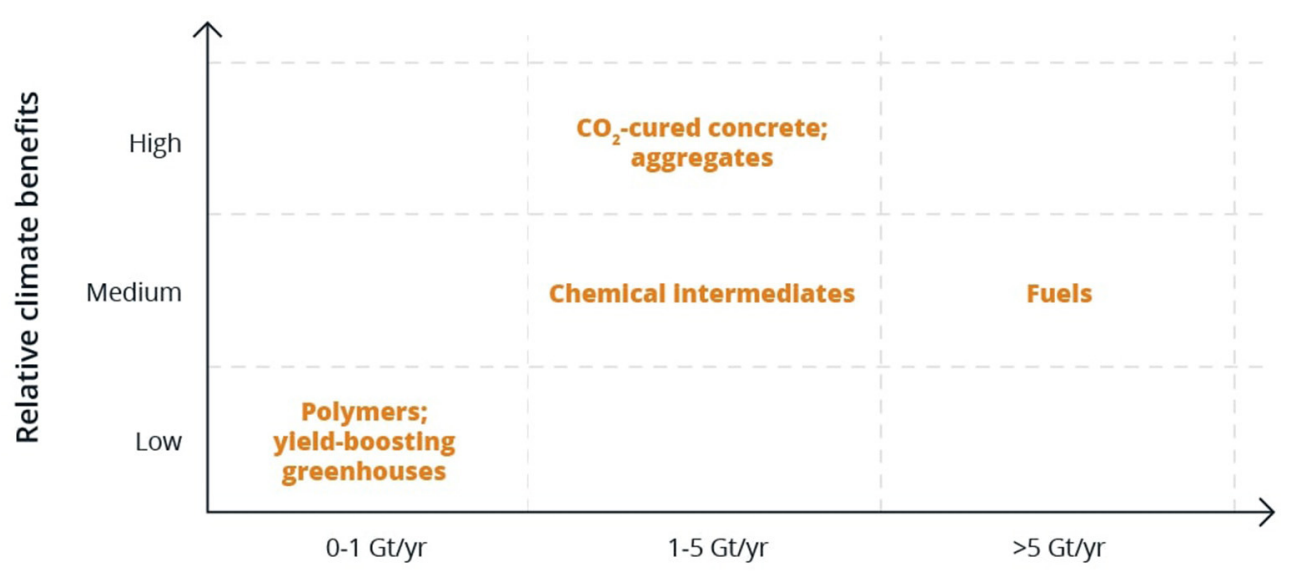

FIGURE 2 | Projected carbon removal potential and climate benefits of $\mathrm{CO}_{2}$-derived products and services adapted from International Energy Agency (2019).

makes it the most immediate and scalable engineered technology pathway for mineralizing industrial $\mathrm{CO}_{2}$, whether captured from industrial point sources or from CDR sources such as bioenergy with carbon capture and storage. Still, many emerging concrete $\mathrm{CO}_{2}$ mineralization technologies are immature and not yet commercially deployed (Ravikumar et al., 2021). This sector therefore presents a crossroads of opportunities: the ability to achieve public decarbonization commitments and support scaling of technologies through the procurement of materials that are already needed for planned infrastructure expansion and renewal.

Portland cement is the definitive, difficult-to-abate global industry. For it to attain carbon neutrality within a timeframe that is meaningful from a climate perspective, breakthrough technologies must quickly emerge and penetrate the market at scale. Therefore, public procurement approaches should be designed to meet the core objective of reducing gross emissions while also explicitly increasing demand for highimpact innovations that the private sector would otherwise be too slow to adopt.

Here we review the potential that low carbon procurement could have to accelerate CCUS deployment by considering a recent policy model. The Low Embodied Carbon Concrete Leadership Act (LECCLA) is a sector-specific CCUS policy targeting the decarbonization of concrete materials purchased by public agencies. LECCLA was introduced separately in the New York (A2591/S542) and New Jersey (A5223) legislatures in 2019 and 2021, respectively (219th Legislature, 2020; Senate Bill S542A, 2021). At the time of this writing the New York legislature has passed legislation requiring consideration of the LECCLA policy mechanism as part of a broader directive to establish a low carbon concrete procurement standard.

\section{POLICY OPTIONS AND IMPLICATIONS}

Before low carbon procurement can occur, existing regulatory standards must be updated. Any requirement or specification that prescribes a certain approach or solution can be a significant obstacle to innovation in procurement (Uyarra et al., 2014). Existing standards may intentionally or inadvertently limit the ability of vendors to compete based on carbon impacts, so these standards must be reviewed and revised for procurement that considers climate impact to be successful.

All low carbon procurement policies must start from the same foundation, which is understanding the carbon content of materials available. If carbon is to be considered a criterion for contract award, it is necessary to be able to transparently contrast and compare bids received. The calculation of the carbon content of materials (referred to as embodied or embedded carbon) is conducted using life-cycle assessment (LCA) methodologies. As defined within the ISO 14040 standard, LCA methodologies study the environmental aspects and potential impacts throughout a product's lifefrom raw materials acquisition through production, use, and disposal (International Organization for Standardization, 2006). LCAs therefore serve as inputs to decision-making for selecting products based on their environmental impacts.

Under LECCLA, this foundational step is accomplished through a requirement for all concrete vendors to complete LCA analyses and report on carbon content. The standardized LCA methodology referred to as a Type III environmental declaration, or Environmental Product Declaration, is the specified reporting tool. The cost to complete these analyses is subsidized through a one-time state tax credit. This incurs a direct cost to the state, though as the number of concrete producers is limited and the credit is capped, the cost is nominal.

With the ability to assess the carbon content of materials wellestablished, the secondary question is how and to what extent carbon should contribute to competitive scoring criteria. Carbon disclosure and reporting may be voluntary or required. Scoring of carbon content may be binary (pass/fail) or incentives-based. Two approaches that have been proposed include:

- Benchmark Threshold (binary model)-To compete for public work, bidders must demonstrate that the carbon content 
of their products meets or exceeds the carbon reduction threshold established by the purchasing agency. Once this requirement is met, there is no additional incentive or consideration offered. Benchmark values are negotiated based on some balance between market readiness and policy ambition. Once established, baselines may be reviewed and adjusted at regular intervals to ensure continual progress. The low carbon fuel standard utilized by the State of California to advance vehicle fuel efficiency is an example of this approach (California Air Resources Board, 2020). This legislation requires fuel suppliers to ensure that the fuel that they sell is at or below a fixed carbon intensity target set by the state. Suppliers that cannot meet this baseline are instead compelled to purchase credits from other suppliers that generate fuels with carbon intensities below the fixed target.

- Competitive Bidding (incentives model)-Bidders are measured against each other's carbon performance during the competitive bidding process. Incentives are offered to the bidder that can provide the lowest impact material, subsidizing investment by the private sector into low carbon technologies. This approach is the basis for LECCLA and mimics the traditional price-based competitive bidding process commonly utilized by public procurement officials. The Dutch $\mathrm{CO}_{2}$ Performance Ladder program is a comparable example that incorporates a discount mechanism directly linking LCA-assessed performance to bid competitiveness. First implemented in 2009 for national infrastructure tendering, the program is now also widely used by local governments across a multitude of sectors, including waste management, information technology, and healthcare (Vastbinder, 2021). Discount incentive mechanisms for procurement also have precedent in domains unrelated to environmental performance. For example, the State of California's Department of General Services applies a $5 \%$ price discount to certified small businesses (California Department of General Services, 2017).

With these elements in place, the only remaining question is to which materials the low carbon procurement policy should apply. Low carbon procurement policy concepts enacted to date such as Buy Clean have been broad-ranging, whereas LECCLA is restricted to one sector.

\section{Challenges}

There is inherent uncertainty in calculating the cost impact of low carbon procurement policies. As the carbon impact of materials is the combined result of many separate activities, selective procurement indirectly targets decarbonization in $\mathrm{CO}_{2}$ sources. LCA calculation methodologies for Scope 3 emissions continue to improve, but any uncertainty in these calculations can make direct comparison of materials challenging and undermine confidence. This concern is reduced when the comparison is made within an individual materials category.

Adding carbon requirements to public tenders necessarily increases the complexity of the tendering process, which may reduce the number of qualified bids received (Cheng et al., 2018). This is compounded by the fact that there is limited awareness of climate policy or "carbon literacy" among procurement professionals. In practice, public procurers operate in an environment where accountability to complex administrative requirements is valued over any individual strategic goal such as decarbonization (Correia et al., 2013). Faced with competing aims, it can be expected that other agendas could be prioritized over decarbonization goals.

The use of voluntary frameworks or poorly defined criteria requirements may undermine the efficacy of any low carbon procurement policy. To effect change, vendors must experience a shift in equilibrium and experience new competitive pressure. Policies with insufficiently ambitious goals and/or weak incentives are unlikely to create this shift. Voluntary frameworks may however be desirable for sectors that are difficult to regulate or when measurement criteria are not fully established.

Understanding the appropriate incentive structure that will lead to change may also be challenging to predict. Experience in the Netherlands under the $\mathrm{CO}_{2}$ Ladder suggests that an incentive as small as $5 \%$ is sufficient to drive change in the low-margin construction sector. Since the introduction of this low carbon procurement policy, total $\mathrm{CO}_{2}$ emissions in the Netherlands have decreased beyond expected rates (Reitbergen et al., 2017). The same incentive for a separate market or jurisdiction however may not achieve equivalent results. Incentives that are too small will fail to generate a change in the market, while incentives that are too large are an inefficient use of public funds.

Policies that utilize a carbon benchmark are subject to gamesmanship and do not generate incentives to go beyond the new benchmark "floor." Benchmarks are necessarily established based on industry data and perspectives on what is possible to achieve, thus an opening is created for industry to lobby for a weaker benchmark than that preferred by the administering agency (Kadefors et al., 2021). Practical experience with policies requiring a benchmark suggests that there is also a significant administrative effort to establish, maintain, and update such benchmarks. Conversely, under the competitive bidding model it may be more difficult to measure and communicate progress due to the lack of a defined benchmark to compare progress against.

\section{ACTIONABLE RECOMMENDATIONS}

When developing effective low carbon procurement policy, evidence from relevant programs and policies suggest several principles for designing a public procurement strategy that can accelerate carbon removal:

\section{Focus on High Potential Sectors}

Initiate low carbon procurement policies in sectors that offer significant opportunities for emissions reduction and where the innovation gap is small. LECCLA focuses on concrete, as this sector is a large source of carbon in the public sector supply chain and is the most technologically mature. This is efficient from a public spending perspective, as these materials are already purchased by the state in large quantities. Leveraging the power of public procurement within a specific sector that is primed for it will provide learning opportunities that can be studied 
and used to inform future procurement approaches in less developed sectors.

\section{Strategically Deploy Incentives}

Contractor decision-making is not strongly driven by internal commitments to environmental performance (Kadefors et al., 2021). As shown by approaches such as the Dutch $\mathrm{CO}_{2}$ Performance Ladder, industry players are responsive to appropriate incentives that tie carbon performance to commercial success (Reitbergen et al., 2017). Selectively using public funds to provide limited incentives in high-impact sectors sends powerful market, social, and political signals. In the context of a low margin commodity sector, even modest discounts applied to bid prices can result in considerable competitive advantages for high performers. LECCLA's maximum $8 \%$ discount for top performers is expected to be sufficient to drive a market response while having a limited fiscal impact.

\section{Utilize a Simple Design}

Low carbon procurement is complex and represents a change in how public procurement agencies operate. Elected officials and procurement professionals are not and cannot be expected to be CDR experts. Successful policies will foster an environment that supports innovation without being overly prescriptive or administratively burdensome. Striking the right balance between a policy that is clearly and rigorously structured while still being approachable so that the market can incrementally learn and adapt is key.

\section{REFERENCES}

219th Legislature (2020). An Act Concerning the Purchase and Use of Low Embodied Carbon Concrete and Supplementing Titles 52 and 54 of the Revised Statutes. Available online at: https://www.njleg.state.nj.us/2020/Bills/A9999/ 5223_I1.HTM (accessed June 29, 2021).

Baron, R. (2016). "The role of public procurement in low-carbon innovation," in Prooceedings of the OECD Background paper for the 33rd Round Table on Sustainable Development (Paris).

Buy Clean California Act. (2017). Public Contract Code Division 2 General Provisions 1100-22355, Part 1 Administrative Provisions 1100-9204, Chapter 3 Formation 3000-3505, Article 5. Available online at: https://www.dgs.ca.gov/ $\mathrm{PD} /$ Resources/Page-Content/Procurement-Division-Resources-List-Folder/ Buy-Clean-California-Act

California Air Resources Board. (2020). Low Carbon Fuel Standard. Available online at: https://ww2.arb.ca.gov/sites/default/files/2020-07/2020_lcfs_fro_ oal-approved_unofficial_06302020.pdf (accessed March 25, 2021).

California Department of General Services. (2017). California Department of General Services State Contracting Manual. Available online at: https://www.dgs.ca.gov/PD/Resources/Page-Content/ProcurementDivision-Resources-List-Folder/State-Contracting-Manual (accessed March 25, 2021).

Cao, Z., Masanet, E., Tiwari, A., and Akolawala, S. (2021). Decarbonizing Concrete: Deep decarbonization pathways for the cement and concrete cycle in the United States, India, and China. Evanston, IL: Industrial Sustainability Analysis Laboratory, Northwestern University.

Cheng, W., Appolloni, A., D’Amato, A., and Zhu, Q. (2018). Green public procurement, missing concepts and future trends-a critical review. J. Clean. Prod. 176, 770-784. doi: 10.1016/j.jclepro.2017.12.027

$\mathrm{CO}_{2}$ Sciences and The Global $\mathrm{CO}_{2}$ Initiative (2016). Global Roadmap for Implementing $\mathrm{CO}_{2}$ Utilization. Ann Arbor, MI: University of Michigan. Available online at: https://deepblue.lib.umich.edu/bitstream/handle/2027.

\section{CONCLUSIONS}

To reach ambitious carbon removal targets of 10GT per year, market signals will be needed beyond the level of investment observed within the private sector to date. As the largest consumers of construction materials like concrete, governments can play a critical role in mobilizing and shaping the development of nascent CCUS and CDR technologies. This can be accomplished directly through procurement and indirectly through policy goals and associated regulatory strategies. As the public sector procures 39\% of all concrete used, procurement that prioritizes lowercarbon products will create demand that accelerates the transition to net zero or even net negative concrete. Without this economic impetus, these technology solutions may emerge too slowly to meaningfully contribute to the carbon removal target.

Although few policy examples exist today, case studies from the Netherlands, California, and New York lay the groundwork for further experimentation and evaluation of options for successful low carbon procurement policies.

\section{AUTHOR CONTRIBUTIONS}

ED was the primary author of this policy brief. CN conducted interviews and provided key insights to the legislative development process. All authors contributed to manuscript revision and read and approved the submitted version.

42/150624/CO2U_Roadmap_FINAL_2016_12_07\%28GCI\%29.pdf (accessed March 25, 2021).

Correia, F., Howard, M., Hawkins, B., Pye, A., and Lamming, R. (2013). Low carbon procurement: an emerging agenda. J. Purch. Supply Manag. 19, 58-64. doi: 10.1016/j.pursup.2012.11.004

Cox, E., Spence, E., and, Pidgeon, N. (2020). Public perceptions of carbon dioxide removal in the United States and the United Kingdom. Nat. Clim. Change 10, 744-749. doi: 10.1038/s41558-020-0823-Z

Czigler, T., Reiters, S., Schulze, P., and Somers K. (2020). Laying the Foundation for Zero-Carbon Cement. Chicago, IL: McKinsey and Company. Available online at: https://www.mckinsey.com/industries/chemicals/our-insights/laying-thefoundation-for-zero-carbon-cement (accessed March 25, 2021).

Govindan, K., Rajeev, A., Padhi, S., and Pati, R. (2020). Supply chain sustainability and performance of firms: a meta-analysis of the literature. Transp. Res. Part E 137, 1-22. doi: 10.1016/j.tre.2020.1 01923

Grandia, J., and Meehan, J. (2017). Public procurement as a policy tool: using procurement to reach desired outcomes in society. Int. J. Public Sect. Manag. 30, 302-309. doi: 10.1108/IJPSM-03-2017-0066

Hasanbeigi, A., and Khutal, H. (2021). Scale of Government Procurement of Carbon Intensive Materials in the U.S. Tampa Bay, FL. St. Petersburg, FL: Global Efficiency Intelligence, LLC. Available online at: https:// www.globalefficiencyintel.com/scale-of-government-procurement-ofcarbonintensive-materials-in-us (accessed March 25, 2021).

Huang, Y. A., Weber, C. L., and Matthews, H. S. (2009). Categorization of scope 3 emissions for streamlined enterprise carbon footprinting. Environ. Sci. Technol. 43, 8509-8515. doi: 10.1021/es901643a

International Energy Agency. (2019). Putting $\mathrm{CO}_{2}$ to Use: Creating Value from Emissions. Paris: International energy Agency.

International Organization for Standardization. (2006). ISO 14040: Environmental Management-Life Cycle Assessment-Principles and Framework, $2^{\text {nd }}$ Edn. Geneva: ISO. 
Kadefors, A., Lingegard, S., Uppenberg, S., Alkan-Olsson, J., and Balian, D. (2021). Designing and implementing procurement requirements for carbon reduction in infrastructure construction-international overview and experiences. $J$. Environ. Plan. Manag., 64, 611-634. doi: 10.1080/09640568.2020.1778453

Keulemans, S., and Van de Walle S. (2017). Cost-effectiveness, domestic favouritism and sustainability in public procurement: a comparative study of public preferences. Int. J. Public Sect. Manag. 30, 328-341. doi: 10.1108/IJPSM-10-2016-0169

Masson-Delmotte, V., Zhai, P., Pörtner, H. O., Roberts, D., Skea, J., Shukla, P. R., et al. (eds.). (2018). Global warming of $1.5^{\circ} \mathrm{C}$. An IPCC special report on the impacts of global warming of $1.5^{\circ} \mathrm{C}$ above pre-industrial levels and related global greenhouse gas emission pathways, in the context of strengthening the global response to the threat of climate change, sustainable development, and efforts to eradicate poverty. IPCC (in press).

Mulligan, J., Rudee, A., Lebling, K., Levin, K., Anderson, J., and Christensen, B. (2020). CarbonShot: Federal Policy Options for Carbon Removal in the United States Working Paper. Washington, DC: World Resources Institute. Available online at: http://www.wri.org/publication/carbonshot-federalpolicy-options-for-carbon-removal-in-the- united-states (accessed March 25, 2021).

Ravikumar, D., Duo, Z., Gregory, K., Shelie, M., Volker, S., and Victor, L. (2021). Carbon dioxide utilization in concrete curing or mixing might not produce a net climate benefit. Nat. Commun. 12, 1-13. doi: 10.1038/s41467-021-21148-w

Reitbergen, M. G., Opstelten, I. J., and Blok, K. (2017). Improving energy and carbon management in construction and civil engineering companiesevaluating the impacts of the $\mathrm{CO}_{2}$ performance ladder. Energy Effic. 10, 55-79. doi: 10.1007/s12053-016-9436-9

Rogelj, J.,Shindell, D., Jiang, K., Fifita, S., Forster, P., and Ginzburg, V., et al. (2018). "Mitigation pathways compatible with $1.5^{\circ} \mathrm{C}$ in the context of sustainable development," in Global Warming of $1.5^{\circ} \mathrm{C}$. An IPCC Special Report on the Impacts of Global Warming of $1.5^{\circ} \mathrm{C}$ Above Pre-Industrial Levels and Related Global Greenhouse Gas Emission Pathways, in the Context of Strengthening the Global Response to the Threat of Climate Change, Sustainable Development, and Efforts to Eradicate Poverty, eds V. Masson-Delmotte, P. Zhai, H.-O. Pörtner, D. Roberts, J. Skea, P.R. Shukla, et al.
Senate Bill S542A. (2021). An Act to Amend the State Finance Law and the Tax Law, in Relation to Implementing "The New York State Low Embodied Carbon Concrete Leadership Act in 2021-2022." Available online at: https:// www.nysenate.gov/legislation/bills/2021/S542 (accessed June 29, 2021).

Trucost. (2016). Sustainable Supply Chain Analysis Executive Summary Report. Available online at: https://www.portlandoregon.gov/brfs/article/627973 (Accessed March 25, 2021).

Uyarra, E., Jakob, E., Javier, G.-E., Luke, G., and Jillian, Y. (2014). Barriers to innovation through public procurement: a supplier perspective. Technovation 34, 631-645. doi: 10.1016/j.technovation.2014.04.003

Vastbinder, M. (2021). "Interviewed by Christopher Neidl," in Personal Interview with the Research and Innovation Manager, $\mathrm{CO}_{2}$ Performance Ladder, Foundation for Climate Friendly Procurement and Business (SKOA).

Conflict of Interest: ED and RN are affiliated with the company Carbon Cure Technologies.

The remaining author declares that the research was conducted in the absence of any commercial or financial relationships that could be construed as a potential conflict of interest.

Publisher's Note: All claims expressed in this article are solely those of the authors and do not necessarily represent those of their affiliated organizations, or those of the publisher, the editors and the reviewers. Any product that may be evaluated in this article, or claim that may be made by its manufacturer, is not guaranteed or endorsed by the publisher.

Copyright (c) 2021 Dunford, Niven and Neidl. This is an open-access article distributed under the terms of the Creative Commons Attribution License (CC BY). The use, distribution or reproduction in other forums is permitted, provided the original author(s) and the copyright owner(s) are credited and that the original publication in this journal is cited, in accordance with accepted academic practice. No use, distribution or reproduction is permitted which does not comply with these terms. 